\title{
Pulmonary sarcoidosis: calcification within the galaxy sign
}

\author{
Shekhar Kunal, Ashok Shah
}

Department of Pulmonary Medicine, Vallabhbhai Patel Chest Institute, University of Delhi, Delhi, India

\section{Correspondence to}

Professor Ashok Shah, ashokshah99@yahoo.com

Accepted 1 December 2016
CrossMark

To cite: Kunal S, Shah A. BMJ Case Rep Published online: [please include Day Month Year] doi:10.1136/ bcr-2016-218187

\section{DESCRIPTION}

A 34-year-old woman had breathlessness, dry cough and low-grade fever for 6 months. Chest X-ray showed bilateral hilar lymphadenopathy and patchy alveolar right mid-zone shadows along with bilateral lower zone nodular opacities (figure 1A). Contrast-enhanced high-resolution CT(HRCT) of thorax demonstrated enlarged, non-necrotic right paratracheal, subcarinal and bilateral hilar lymph nodes. The lung window in right upper lobe revealed a large nodule with irregular margins encircled by multiple small nodules suggestive of 'galaxy' sign (figure 1B). In addition, mediastinal window divulged dense calcification within the nodule and mediastinal lymphnodes (figure 1C). Fibreoptic bronchoscopy visualised multiple endobronchial granulomatous lesions throughout the tracheobronchial tree (figure 2A) and was confirmed on biopsy (figure 2B). The diagnosis of pulmonary sarcoidosis was based on (1) chest imaging, (2) elevated serum ACE levels $(126 \mathrm{IU} / \mathrm{mL}$ [8-65 IU/mL]), (3) negative tuberculin test and (4) visible endobronchial lesions and histopathological confirmation of non-caseating granulomas.

The 'galaxy sign', on HRCT, was first described in sarcoidosis. ${ }^{1}$ It refers to a pulmonary nodule, $1-2 \mathrm{~cm}$ in size with irregular margins that are surrounded by multiple tiny satellite nodules. This is formed due to the concentration of small nodules, which become less dense towards the periphery causing the perimeter to be irregular. The smaller nodules represent interstitial granulomas. ${ }^{2}$ This appearance resembles that of a galaxy hence the name. ${ }^{1}$ This sign has now also been documented in pulmonary tuberculosis ${ }^{3}$ along with calcification within the nodule. To the best of our knowledge, this is the first documentation of calcification within the nodule suggestive of 'galaxy sign' in pulmonary sarcoidosis.

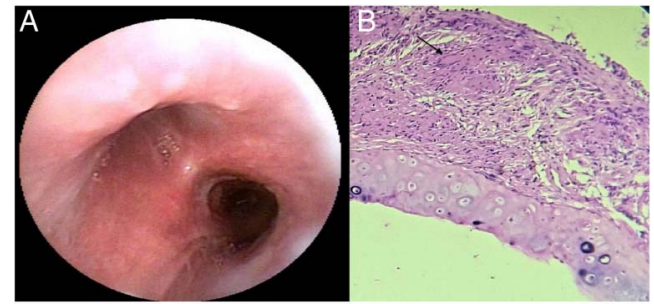

Figure 2 (A) Fibreoptic bronchoscopic image showing multiple endobronchial granulomatous lesions; and (B) medium-power view $(\times 10)$ of the patient's biopsy specimen on $\mathrm{H} \& \mathrm{E}$ stain showing non-caseating granuloma (black arrow).

\section{Learning points}

- The 'galaxy' sign on high-resolution CT of the thorax is a more recently but rarely described feature in pulmonary sarcoidosis and is a pointer towards the diagnosis. This has also been reported in pulmonary tuberculosis.

- This sign represents a large nodule $1-2 \mathrm{~cm}$ in size with an irregular margin surrounded by multiple smaller nodules resembling a galaxy. This parenchymal nodule is due to coalescence of smaller nodules, concentrated in the centre but less dense peripherally leading to irregular margins.

- Calcification within the nodule, a feature previously described in pulmonary tuberculosis, is being reported for the first time in a 'galaxy' sign due to pulmonary sarcoidosis.

Contributors SK and AS collected the clinical data; reviewed the literature; drafted the manuscript and have read and approved the

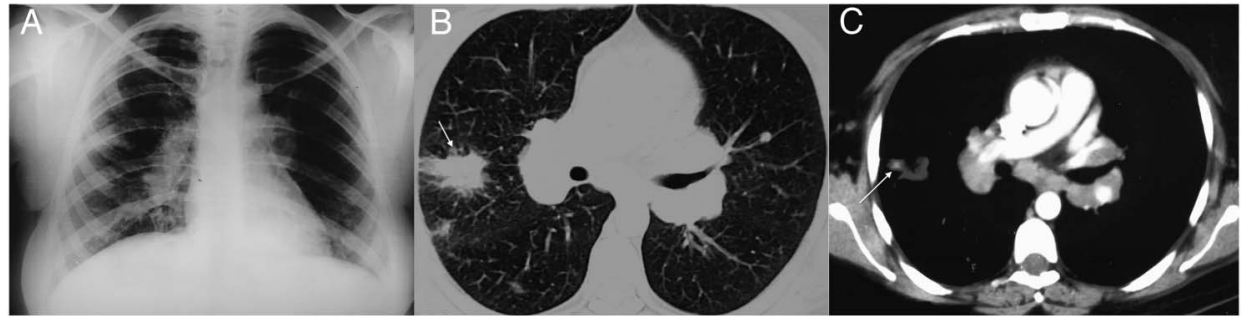

Figure 1 (A) Chest X-ray showing bilateral hilar lymphadenopathy and patchy alveolar right mid-zone shadows along with bilateral lower zone nodular opacities; (B) HRCT of the thorax (lung window) showing a large nodule with irregular margins in the right upper lobe being encircled by multiple small nodules suggestive of 'galaxy' sign (white arrow) and (C) HRCT of the thorax (mediastinal window) showing dense calcification within the nodule (white arrow) and calcified mediastinal lymphnodes. HRCT, high-resolution CT. 
final manuscript. AS is responsible for the genuineness of the data, the concept and is also the guarantor of the paper.

Competing interests None declared.

Patient consent Obtained.

Provenance and peer review Not commissioned; externally peer reviewed.

\section{REFERENCES}

1 Nakatsu M, Hatabu H, Morikawa K, et al. Large coalescent parenchymal nodules in pulmonary sarcoidosis: "sarcoid galaxy" sign. AJR Am J Roentgenol 2002;178:1389-93.

2 Aikins A, Kanne J, Chung J. Galaxy sign. J Thorac Imaging 2012;27:337-8.

3 Heo JN, Choi YW, Jeon SC, et al. Pulmonary tuberculosis: another disease showing clusters of small nodules. AJR Am J Roentgenol 2005;184:639-42.

Copyright 2016 BMJ Publishing Group. All rights reserved. For permission to reuse any of this content visit

http://group.bmj.com/group/rights-licensing/permissions.

BMJ Case Report Fellows may re-use this article for personal use and teaching without any further permission.

Become a Fellow of BMJ Case Reports today and you can:

- Submit as many cases as you like

- Enjoy fast sympathetic peer review and rapid publication of accepted articles

- Access all the published articles

- Re-use any of the published material for personal use and teaching without further permission

For information on Institutional Fellowships contact consortiasales@bmjgroup.com

Visit casereports.bmj.com for more articles like this and to become a Fellow 